\title{
How much coughing is normal?
}

\author{
Paul Munyard, Andrew Bush
}

\begin{abstract}
A new multiparametric device (RBC-7) was used for recording cough in ambulatory children over a 24 hour period. The number of coughs and the pattern of coughing can easily be studied with the aid of a personal computer and dedicated computer software. Forty one 'normal' children were recorded, identified from a primary school with the aid of a questionnaire. They were free from any respiratory infection for one month, and had a normal examination and spirometry immediately before recording. Cough frequency was 11.3, range 1 to 34, cough episodes per 24 hours. This was unaffected by passive smoking or the presence of furry pets in the home. Nocturnal and prolonged coughing was unusual in these children. The device was highly acceptable to the children, and no adverse effects were reported. Such objective data on cough outside the laboratory setting are unique, help to determine what is normal, and may help in the diagnosis and assessment of many respiratory diseases.

(Arch Dis Child 1996;74:531-534)
\end{abstract}

Keywords: cough, normal child, monitoring.

Respiratory illness, both acute and chronic, is common in childhood, and accounts for $30 \%$ of all consultations with general practitioners for children under the age of 11 years. ${ }^{1}$ Studies in Britain have found a prevalence for asthma of $11-15 \%$ in schoolchildren. ${ }^{2}{ }^{3}$ In childhood asthma cough may be the most frequent symptom $^{4}$ or its only symptom, ${ }^{5}$ yet it remains difficult to assess. Conversely, cough may be due to many non-asthmatic conditions, and the existence of pure cough variant asthma has been questioned. ${ }^{6}$ Reporting of nocturnal cough with asthma diaries has repeatedly been found to show poor agreement with recorded cough. ${ }^{7}{ }^{8}$ Reported cough may be an important factor leading to an increase in treatment for asthma, which may be inappropriate, and there is concern over the side effects, particularly on growth, of higher doses of inhaled steroids that some patients are prescribed for symptom control. ${ }^{-11}$ There are no objective data on 'normal cough' in children. The purpose of this study is to report on how much normal children cough.

\section{Methods}

A single primary school was approached. Approval for the study was obtained from the children, parents, educational authorities, and the hospital ethics committee.
A new recording device, the $\mathrm{RBC}-7$, with a notebook computer setup procedure was demonstrated to the children. Those who wished to participate collected a questionnaire and consent form, which they took home for parents to complete. Once full consent was obtained up to six children per day were recorded for a full 24 hour period, from one school day to the next.

Forty four children were recorded, aged $8-12$ years ( 16 boys, 28 girls). The parent completed questionnaire (shown as an appendix to this paper) included questions on the child's personal and family history of atopic and other respiratory diseases, respiratory illness in the previous four weeks, medications (both previous and present), pet ownership, parental occupation, and smoking habits. Only children with no personal or family history of asthma (in first degree relatives), and who had never been prescribed antiasthma medication, were recruited.

The children were seen at school, their heights measured, they were examined for evidence of an upper respiratory tract infection (URTI), their chest shapes inspected, and auscultation performed. Flow-volume loops were performed with a portable spirometer (Vitalograph, Buckinghamshire, UK). The flowvolume loop with the highest forced expiratory volume in one second $\left(\mathrm{FEV}_{1}\right)$ was recorded, after at least three attempts.

This study used the RBC-7 device (fig 1) for recording cough in ambulatory children over a 24 hour period. We have previously described and validated this device in adults and children. ${ }^{12}$ Briefly the RBC-7 is a multiparametric recording device, worn in a waist bag, connected to the chest with three electrocardiographic (ECG) leads, three electromyographic (EMG) leads, and a microphone. An accelerometer placed in the waist bag gives information on the level of activity. The device is set up with the aid of a notebook computer and this process takes 5-10 minutes. Gains are set for each recording channel individually for the subject. Cough is recorded in two modes, an EMG and an audio signal. The EMG filtering is such that voluntary muscle movement is filtered out, and the rapidly recruited abdominal wall muscles involved in coughing are recorded. Simultaneously the audio signal of the cough is recorded, giving two signals from which to verify the cough.

The information obtained is displayed visually on a personal computer (PC), in contracted or expanded formats (fig 2). All data collected were inspected, and automatic analysis was not used. The RBC-7 gives data on the quantity and pattern of coughing both during the day and at night. In addition, data recorded 
Table 1 Characteristics of 41 children studied

\begin{tabular}{lcc}
\hline Characteristic & Male $(n=16)$ & Female $(n=25)$ \\
\hline Age, mean & 9.6 years & 10.0 years \\
Height, mean (range) & $136.7 \mathrm{~cm}(122$ to 152$)$ & $139.2 \mathrm{~cm}(118$ to 160$)$ \\
FEV \% predicted, mean (range) & $95.6(75$ to 117$)$ & $88(71$ to 104$)$ \\
FVC \% predicted, mean (range) & $95.6(73$ to 117$)$ & $91.3(67$ to 107$)$ \\
PEFR \% predicted, mean (range) & $96.2(84$ to 119$)$ & $89.6(70$ to 112$)$ \\
\% Passive smoking & 25 & 32 \\
\% Furry pets & 25 & 64 \\
\hline
\end{tabular}

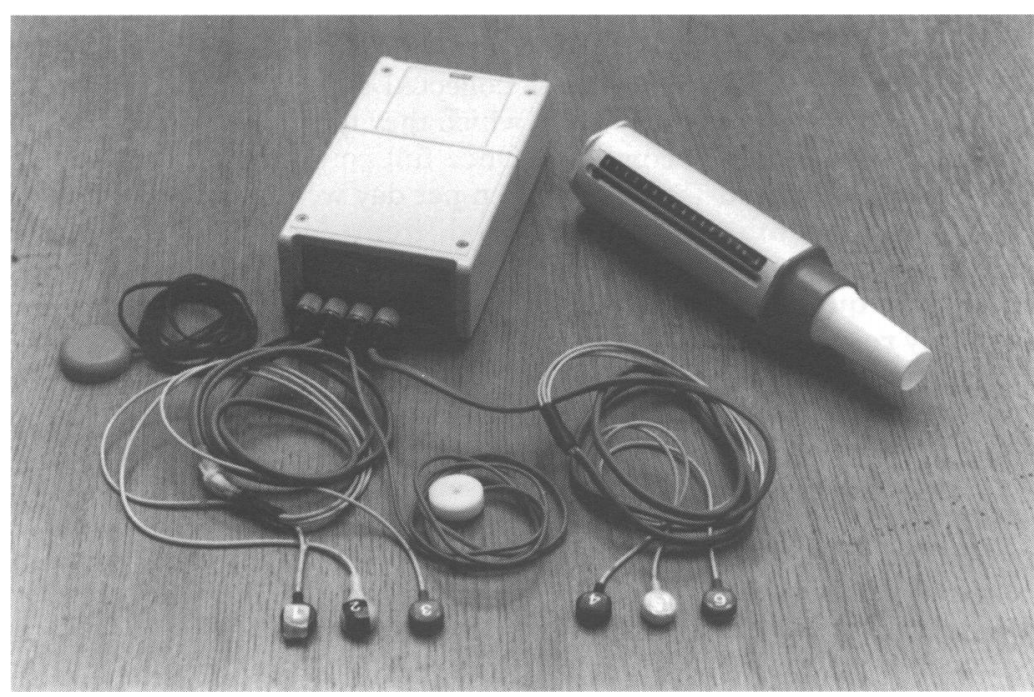

Figure 1 RBC-7 Multiparametric recording device (with peak expiratory flow meter for size comparison).

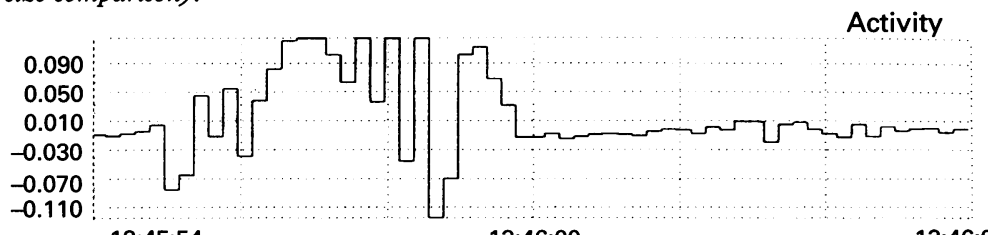

$13: 45: 54$

13:46:00

$13: 46: 06$

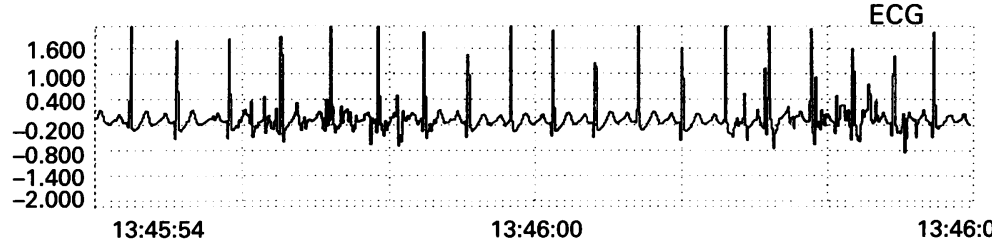

Heart rate

180.00

150.00

120.00

90.000

60.000

30.000

$13: 45: 54$

13:46:00

$13: 46: 06$
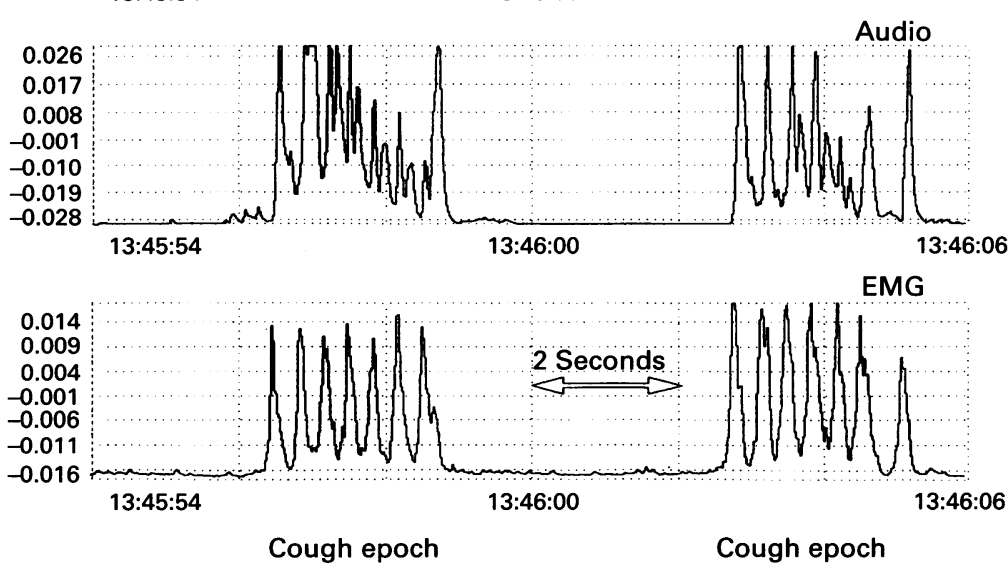

Figure 2 A screen print out of activity, ECG, heart rate, and cough on audio and EMG channels, over a 12 second period. include heart rate and a measure of activity from an accelerometer, so that cough can be related to exercise. The $\mathrm{RBC}-7$ is set up to record intermittently, and is triggered to record any EMG activity above an individualised threshold. It also records 10 seconds of data every 15 minutes, which ensures that we can detect if the device has been removed.

Once the device was set up, the children were encouraged to participate fully in normal activities, the only limitation being that they should not submerge the device in water.

\section{Results}

Three children were excluded as they had current upper respiratory tract infections (URTI) when examined by one of us (PFM), or a history of such infection within the last four weeks. The details of the 41 'normal' children are shown in the table. We arbitrarily defined episodes of cough as a period of cough EMG peaks with less than 2 seconds of baseline activity between the peaks, and a prolonged coughing bout as one with at least 10 EMG peaks. This had to be an arbitrary definition and was based on our experience of these normal children and a limited experience of children with respiratory disease.

These children show a mean number of episodes of cough of 11.3 per 24 hours, with a range of 1 to 34 . The pattern of coughing over the course of the 24 hour period is shown as the mean number of cough episodes per hour in fig 3. Only two of the 41 children had coughing at night, one child having one episode, the other three episodes. 'Night' was taken as the time when activity ceased, and heart rate slowed, and the difference is easily detected by the device.

There was no correlation between the number of cough episodes and their $\mathrm{FEV}_{1}$ recorded at the start of the 24 hour recording, with the correlation coefficient of 0.017 . In this study five of the 41 children had prolonged coughing bouts (range 1 to 7 ). There was no statistically significant difference between the number of cough episodes or the number of prolonged coughing episodes between children who had furry pets at home, or between children who had at least one parent who admitted to smoking.

A separate group of three children, who were otherwise 'normal' were recorded when they had upper respiratory tract infections. They had 10,14, and 100 cough episodes recorded, two having prolonged coughing bouts. None had nocturnal cough.

\section{Discussion}

This study showed that the mean number of cough episodes for 'normal' children was 11.3 per 24 hours, with a range of 1 to 34 . Only two children coughed at night, and five had prolonged bouts of coughing. We feel that we have identified a group of as normal children as is possible. Children were recruited only if they had no first degree relative with asthma, had never been diagnosed as asthmatic, and had never been given asthmatic medication. The 


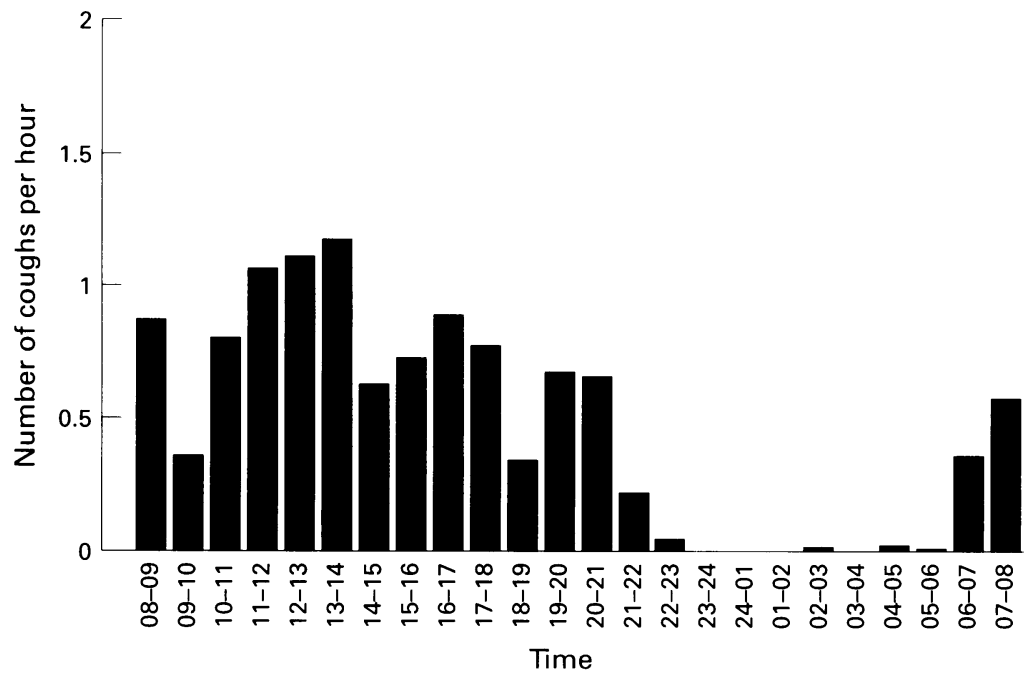

Figure 3 Mean number of cough episodes per hour.

\section{Appendix}

Questionnaire for completion by parents. ${ }^{5}$

Please answer the following questions:

ALL ANSWERS WILL BE TREATED IN STRICT CONFIDENCE

NAME of child. BOY/GIRL

Date of birth of child.

Has he/she had a cold or chest infection in the last month?

YES NO

Has he/she ever had asthma? if yes, write age first diagnosed..

YES NO

Does he/she have asthma now?

YES NO

Has he/she ever wheezed? (made a whistling sound on breathing out)

YES NO

Does he/she cough......NEVER.......SOMETIMES......OFTEN......CONSTANTLY.

Has he/she ever been prescribed Ventolin or Bricanyl?....if yes when?

YES NO

Has he/she ever had eczema or hay fever?

YES NO

Does he/she have eczema or hay fever now?

YES NO

Does he/she have any other chest complaint? please name.

YES NO

Does anyone else in the family have any of the following

asthma YES/NO if yes who?...............

eczema YES/NO if yes who?......

hay fever YES/NO if yes who?.....

Please give relationship to the child

Do you have any pets?

if yes please name

YES NO

Does anyone in the family smoke?

If so who?.

YES NO

Fathers occupation

..Mothers occupation

If you agree to your child participating in this study please sign below, and give this form to your child to give to me at school.

I(name)........

being the parent or guardian of(name of child)

consent to him/her participating in a study of cough recording described above.

SIGNED.

DATE

information was accumulated by questionnaire, and we were not able to validate it objectively. They were then examined and flowvolume loops performed on a portable spirometer. The range of percentage predicted $\mathrm{FEV}_{1}$ was $71 \%$ to $117 \%$. These children had never performed any kind of lung function testing before, and constraints of time during the school day mean that usually only three to five attempts were made. The shape of the flow-volume loops was normal. It is possible that with further practice the children scoring below $85 \%$ of predicted could have achieved higher values. Twelve children scored below $85 \%$ of predicted on $\mathrm{FEV}_{1}$, with a mean number of cough episodes of 9.0 per 24 hours. Excluding these children did not alter the mean number of cough episodes for the remaining children. There was no correlation between the 'one off' spirometry measurement and the number of cough episodes. With a relatively small group of children, and perhaps the inaccuracies of questionnaires asking about smoking habits, it is not surprising that this small study did not find any significant difference in cough episodes between children who had smoking parents or furry pets at home.

This paper addresses the question 'how much do normal children cough?' There are many epidemiological studies comparing the symptom of wheeze to disease diagnosis, ${ }^{2}{ }^{13}$ but far fewer studies looking at the prevalence of other respiratory symptoms (including cough) in children. Clifford tried to identify abnormal cough by asking parents "has your child ever seemed to cough more (or to get more coughs) compared to other children?' One third of parents of 7 year olds thought that their child coughed more than others. ${ }^{14}$ Whereas statistically this is probably accurate, the clinical validity of such measurements must be questioned. These studies are based on a parent completed questionnaire, with the majority of children being healthy. When comparisons have been made between parent completed diaries and actual tape recordings of the child at night, no association was found between reported and recorded nocturnal cough. ${ }^{7}{ }^{8} \mathrm{It}$ is likely that parents receiving a questionnaire are even less likely to be accurate in their reporting compared to diagnosed asthmatic children involved in a study with home monitoring equipment.

In a review of cough in children, Beardsmore and Simpson comment that the incidence of cough varies in different populations, and may be influenced by factors such as atmospheric pollution. ${ }^{15}$ This does not, however, address the question of how much coughing is normal.

An advantage of our study is that for the first time objective data are used, rather than relying on subjective symptom perception and reporting.

We have previously validated the RBC-7 for its ability to record cough. ${ }^{12}$ Since the cough signal is recorded simultaneously on both the EMG and audio channels, and most voluntary muscle activity filtered out, the cough signal is less open to misinterpretation than if either signal were recorded alone. This is especially important when recording active children during normal activities including attending school and playing sports, when shouting or 
vigorous activity may be common. The review of data visually on the computer screen means that even though an audio signal is recorded there is no invasion of privacy.

This device offers a unique opportunity to obtain objective data on cough in ambulatory children. The pattern of coughing may also help in the diagnosis and assessment of respiratory illness. Epidemiological studies with the aid of this device may answer questions on coughing with URTI. The aim of this study was to look at normal children, but it included three children with URTI. One of these children had 110 cough episodes recorded, well in excess of the normal children who did not have any URTI.

We have established that normal apparently healthy children do cough, with a mean value of 11.3 episodes per 24 hours. This ambulatory device may be extremely useful in the diagnosis and monitoring of asthma and other respiratory conditions. It proved highly acceptable to the children and no adverse effects were encountered. It is capable of giving objective information on cough and relating this to time and activity.

1 Royal College of General Practitioners, Office of Population Census and Surveys, Department of Health and Social
Security. Morbidity statistics from general practice 1981-1982: third national study. London: HMSO, 1986.

2 Lee DA, Winslow NR, Speight AN, Hey EN. Prevalence and spectrum of asthma in childhood. $B M \mathcal{F}^{\prime} 1983 ; 286: 1256-8$. Stachan DP, Anderson HR, Limb ES, O'Neill A, Wells N. A national survey of asthma prevalence, severity, and national survey of asthma prevalence, severity, and
treatment in Great Britain. Arch Dis Child 1994;70:174-8.

treatment in Great Britain. Arch Dis Child 1994;70:174-8.
4 Humphries T, Weinberger M, Vaughan L, et al. Demogumphries $T$, Weinberger $M$, Vaughan $L$, et al. Demo-
graphic and clinical characteristics of childhood asthma [abstract]. $\mathcal{F}$ Allergy Clin Immunol 1985;75:197.

5 Anonymous. Cough and wheeze in asthma: are they interdependent? Lancet 1988;i:447-8.

6 McKenzie S. Cough-but is it asthma? Arch Dis Child 1994; 70:1-2.

7 Falconer A, Oldman C, Helms P. Poor agreement between reported and recorded cough nocturnal cough in asthma. Pediatr Pulmonol 1993;15:209-11.

8 Archer LNJ, Simpson H. Night cough counts and diary card scores in asthma. Arch Dis Child 1985;60:473-4.

9 Law CM, Honour JW, Marchant JL, Preece MA, Warner JO. Nocturnal adrenal suppression in asthmatic children Nocturnal adrenal suppression in asthmatic children
taking inhaled beclomethasone dipropionate. Lancet 1986; taking in $942-4$.

10 Kamada AK, Parks DP, Szefler SJ. Inhaled glucocorticoid therapy in children: how much is safe? Pediatr Pulmonol 1992;12:71-2.

11 Wothers OD, Pedersen S. Growth of asthmatic children during treatment with budesonide: a double blind trial. $B M \mathcal{F}$ 1991;302:627-8.

12 Munyard P, Busst C, Logan-Sinclair R, Bush A. A new device for ambulatory cough recording. Pediatr Pulmonol 1994;18:178-86.

13 Hill RA, Standen PJ, Tattersfield AE. Asthma, wheezing, and school absence in primary schools. Arch Dis Child 1989;64:246-51.

14 Clifford R, Radford M, Howell JB, Holgate ST. Prevalence of respiratory symptoms among 7 and 11 year old schoolof respiratory symptoms among 7 and 11 year old school-
children and association with asthma. Arch Dis Child 1989;64:1118-25.

15 Beardsmore CS, Simpson H. Cough in children. 7 Asthma 1991;28:309-21. 